\title{
KANT CONTRA HABERMAS: GUERRA E PAZ NO PENSAMENTO COSMOPOLITA
}

\author{
[ Kant against Habermas: War and Peace in Cosmopolitan Thought ]
}

\author{
Aylton Barbieri Durão * \\ Universidade Federal de Santa Catarina, Brasil
}

\begin{abstract}
Resumo: Resumo: Em seu artigo de 1995, comemorativo dos 200 anos da obra Rumo à paz perpétua de Kant, Habermas fez uma série de críticas tanto normativas como históricas acerca do cosmopolitismo kantiano. A primeira delas assinala o caráter negativo do conceito de paz: (1) porque, como pensador do século XVIII, Kant desconhecia o sentido da guerra total e; (2) não considerava as mudanças necessárias nas condições econômicas, sociais e culturais necessárias para fomentar a paz. Contudo, o projeto kantiano de paz apresenta um sentido positivo na medida em que a paz depende de reformas políticas que propiciem o desenvolvimento da constituição republicana, ao mesmo tempo em que uma tensão irremediável entre guerra e paz possibilita uma aproximação constante à paz perpétua e exige um espírito de liberdade negativa tanto religiosa como econômica.
\end{abstract}

Palavras-Chave: Habermas; Kant; cosmopolitismo; paz; guerra
AbSTRaCT:Abstract: In his 1995 article, commemorative of 200 years of work Towards Perpetual Peace Kant, Habermas makes a lot of criticism both normative and historical about the Kantian cosmopolitanism. The first marks the negative character of the concept of peace: (1) because, as a thinker of the eighteenth century, Kant was unaware of the meaning of total war and; (2) did not consider the necessary changes in the economic, social and cultural rights necessary to promote peace. However, the Kantian project of peace presents a positive sense in that peace depends on political reforms that foster the development of the republican constitution at the same time that an irremediable tension between war and peace enables a constant approach to perpetual peace and demands a the spirit of negative liberty both religious and economic.

KEYwORDS: Habermas; Kant;

\section{INTRODUÇÃO ${ }^{1}$}

Z $m$ 1995, Habermas apresentou um artigo comemorativo do bicentenário de

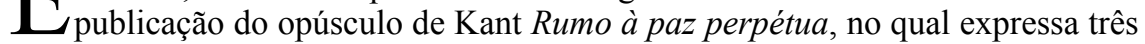
ideias básicas: inicialmente, pretende avaliar os argumentos normativos e históricos kantianos sobre o projeto de paz perpétua à luz do transcurso dos últimos 200 anos; em seguida, aspira oferecer uma versão transformada do cosmopolitismo kantiano em decorrência da necessidade de responder aos desenvolvimentos históricos contemporâneos, os quais experimentaram uma espécie de dialética, pois, se a

* Professor associado do Departamento de Filosofia da Universidade Federal de Santa Catarina. Doutor em filosofia pela Universidad de Valladolid (2003)/Espanha. Áreas de interesse: filosofia política e filosofia do direito, principalmente nos temas relacionados à razão prática em Kant e Habermase sobreorepublicanismo.m@ilto: barbieri@cfh.ufsc.br 
princípios foram desmentidos, acabaram ocorreram ao menos parcialmente como idealizados pelo filósofo de Königsberg e; por fim, responde a uma polêmica imaginária entre os kantianos e Carl Schmitt, que estava historicamente situada no final do século $\mathrm{XX}$, mas possui relevância conceitual atemporal, em virtude de uma renovação do argumento realista schmittiano contra os kantianos de que a moralização da política internacional, realizada mediante a intervenção humanitária para a proteção dos direitos humanos, longe de conduzir a um ideal de paz entre os estados, implica demonizar o inimigo e transformar as guerras limitadas vigentes durante a Modernidade em guerras totais.

Evidentemente que este artigo de Habermas discute uma gama de questões extremamente ampla e complexa, por isto, pretende-se tratar somente do primeiro dos seus argumentos normativos no qual afirma que o cosmopolitismo kantiano apresenta apenas um conceito negativo de paz, o qual desenvolve em dois argumentos, sendo que o primeiro possui duas partes: (1a) inicialmente afirma que Kant possui unicamente um conceito negativo de paz porque o seu projeto se resume ao veto da razão prática segundo o qual "não deve haver guerra" porque o seu pensamento está localizado no final do século XVIII, onde vigoravam as guerras limitadas resultantes da Paz da Vestfália e desconhecia as guerras totais do século XX, por isso, seu conceito de paz era tão limitado como o próprio conceito de guerra ${ }^{2}$ e, consequentemente, (1b) Kant condenava os crimes de guerra, mas não a própria guerra como um crime ${ }^{3}$; (2) por outro lado, também em virtude de seu pensamente estar localizado no final do século XVIII, Kant pensava a-historicamente e, obviamente, não levava em consideração a necessidade de uma intervenção positiva nas condições econômicas, sociais e culturais indispensáveis para fomentar a paz no mundo de hoje, dividido entre estados que já se constituíram como estados democráticos de direito, os quais cumprem as condições necessárias para a paz, estados que precisam compensar esta carência mediante o reforço da soberania interna e externa com governos autoritários e estados que são tão frágeis que não conseguem sequer regular a ordem interna ${ }^{4}$.

\section{I}

\section{A PAZ É TÃo LIMITAdA COMO A PRÓPRIA GUERRA?}

Habermas considera fundamental a afirmação de Kant na "Conclusão" da Doutrina do direito, que denominou o "veto da razão prática", segundo a qual "não deve haver guerra" porque ela indicaria que o filósofo de Königsberg possui somente um conceito negativo de paz. Isto fica patente no fato de que Kant não faz referência às vítimas e ao seu sofrimento, mas somente aos custos e prejuízos que as guerras acarretam. Também chama a atenção a sua exigência de um controle fraco, promovido unicamente pela moral, de práticas por ele consideradas inaceitáveis como o recurso de assassinos, envenenadores, espiões, incitação da traição ou rompimento de acordos de rendição expostos no $6^{\circ}$ artigo preliminar do projeto de paz, sem fazer referência a formas mais brutais de violação dos direitos humanos e aos genocídios ocorridos no século $\mathrm{XX}^{5}$.

Isso ocorreu porque Kant pensaria a partir do contexto da Paz da Vestfália, iniciada em 1648, depois que uma série de acordos de paz pôs fim a uma sucessão de conflitos que aconteciam na Europa na primeira metade do século XVII, do qual o mais 
destacado era a Guerra dos Trinta Anos entre o imperador do Sacro Império Romano Germânico contra alguns príncipes eleitores e outros estados como a Suécia e a França em função das guerras religiosas entre católicos e protestantes. A conclusão destes vários tratados de paz formou um equilíbrio das potências europeias, o qual era controlado mediante uma vigilância recíproca entre estas potências, devido ao temor de que a superioridade de uma delas pudesse reavivar a situação de violência descontrolada anterior. Esta situação de equilíbrio tenso entre as potências acabou fomentando uma forma da razão de estado caracterizada por um modelo de soberania no qual, internamente, um déspota com poderes absolutos deveria manter a segurança através do monopólio da violência legal enquanto, externamente, deveria promover a independência do estado em relação aos demais, com base no princípio da afirmação do seu connatus, segundo o qual um estado que não se expande constantemente acaba definhando e morrendo (como ocorre pela conquista estrangeira) por meio de guerras prudentes entre exércitos regulares e com objetivos definidos e limitados, os quais, uma vez alcançados, determinariam o final do conflito, para não despertar a suspeita das demais potências e atrair sobre si uma aliança de inimigos ${ }^{6}$.

Esta circunstância de guerra e paz resultante do equilíbrio das potências europeias contrasta profundamente com a situação contemporânea, descrita pelo termo desenvolvido pelos nazistas de "guerra total", porque ela é ilimitada em todos os níveis: (1) no plano dos agentes, as guerras totais dificilmente ocorrem somente entre estados soberanos, o que dificulta a identificação dos implicados, mas, em muitos casos, envolvem estados contra organismos não-estatais definidos como terroristas, ou, em virtude do temor de uma guerra nuclear, não permite um conflito direto entre as potências hegemônicas, mas se caracteriza por uma prolongada guerra fria na forma de uma destruição de recursos em competições esportivas, culturais, científicas e em conflitos limitados em países satélites, ou ainda acontecem guerras civis entre grupos diferenciados por fatores étnicos, ideológicos ou religiosos dentro do mesmo estado, ou ocorrem genocídios e guerras de limpeza étnica; (2) no plano dos afetados, o emprego sem precedentes de tecnologias de destruição, como armas nucleares, químicas, biológicas e até cibernéticas, atinge toda a população, até mesmo a dos estados que não estão diretamente envolvidos no próprio conflito, não se limitando somente os combatentes, mas causando principalmente vítimas civis; (3) no plano dos objetivos, os conflitos não são realizados com uma intenção definida, como a conquista de um território ou a obtenção de um recurso econômico, por exemplo, o qual, uma vez alcançado, determina o fim do conflito, porque, em geral, as guerras agora ocorrem por razões ideológicas (sejam políticas ou religiosas) que só podem terminar com improvável derrota total do inimigo a nível planetário; (4) no plano da dimensão, os conflitos tendem a se estender espacialmente a um número crescente de estados e outros tipos de atores, bem como temporalmente passam a não ter um marco preciso que define o começo e o término das hostilidades, até porque, em muitos destes conflitos, raramente acontece uma declaração formal de guerra ou a rendição de uma das partes ou a assinatura de um acordo de armistício e muito menos um tratado de paz, ainda que possa ocorrer uma interrupção multilateral das hostilidades ${ }^{7}$.

Como Kant não conhecia o conceito de guerra total, ilimitada no que se refere aos atores, aos afetados, aos objetivos e as dimensões porque pensava a partir do contexto histórico das guerras limitadas do século XVIII, então, ele desenvolveu um conceito de paz tão limitado como o próprio conceito de guerra, a qual pode ser alcançada simplesmente por uma formulação negativa "não deve haver guerra". Por isso Habermas considera que as guerras totais contemporâneas demandam uma ação 
positiva realizada por uma organização cosmopolita dotada de poder coativo e capaz de regulamentar as relações internacionais ${ }^{8}$.

Evidentemente que os grandes filósofos, como Habermas, não costumam ser bons historiadores da filosofia, porque a sua preocupação não é comentar fielmente o pensamento dos filósofos anteriores, mas utilizá-los para expor a sua própria teoria. Neste sentido, a intenção de Habermas consiste em interpretar o pensamento kantiano preparando as condições para apresentar a sua versão modificada do cosmopolitismo à i luz das transformações históricas ocorridas nos últimos 200 anos. Por isso, uma análise mais detida no pensamento kantiano revela que existe um conceito positivo de paz em seu projeto cosmopolita, o qual consiste na reforma gradual da legislação até uma aproximação assintótica de um tríplice sistema de direitos: a constituição republicana, no âmbito do direito político, a federação de estado no plano do direito das gentes e ao direito cosmopolita, que constitui uma novidade introduzida por ele ${ }^{9}$.

No final do século XVIII, Kant pens a filosofia política sob o impacto das duas grandes revoluções: a Revolução Americana e a Revolução Francesa. Ambas as revoluções adotam o modelo republicano como forma de governo, o qual Kant considera o único capaz de promover a paz perpétua porque, em um estado autoritário, o déspota não perde nada com as guerras, pois esta não afeta as suas caçadas ou os seus banquetes, mas em uma forma de governo em que o súdito (ou seja, aquele que obedece a lei) é, ao mesmo tempo, cidadão (o autor da lei) e deve, portanto, decidir se haverá guerra, a qual terá que custear com o pagamento de impostos e com os sacrifícios pessoais que esta comporta, então, dificilmente dará o seu consentimento para um empreendimento tão custoso ${ }^{10}$.

Embora a Revolução Francesa seja mais celebrada nos textos kantianos, ainda que ele não a interprete como uma revolução, mas como uma transferência da soberania do Rei Luis XVI para a Assembleia Nacional, na medida em que este convoca os Estados Gerais para resolver os graves problemas econômicos do reino, pois Kant nega a legitimidade jurídica do direito de resistência dos súditos com relação ao soberano ${ }^{11}$, inclusive nos casos em que este cometa uma injustiça flagrante, a verdade é que o modelo republicano adotado por Kant se assemelha muito mais ao das pequenas repúblicas que se formaram na América do Norte, após a independência das treze colônias, bem como da confederação que elas constituíram antes da adoção do federalismo resultante da Constituição de 1787, embora a única referência explícita de Kant sobre o modelo político adotado nos EUA seja justamente uma crítica a este modelo constitucional ${ }^{12}$.

O modelo republicano kantiano reflete, por um lado, a tradição do pensamento republicano ${ }^{13}$ e, por outro, as discussões e institucionalizações adotadas nessas duas repúblicas emergentes, das quais se podem obter algumas características específicas: (1) embora estas revoluções comecem com uma solução de compromisso entre os ideais jurídicos liberais, segundo o qual o homem é portador de direitos inalienáveis, e republicanos, de acordo com o qual todo direito emana da vontade soberana do povo, manifesto na Declaração dos Direitos do Homem e do Cidadão da França e na Declaração de Independência dos EUA, o curso da revolução levou a uma visão majoritariamente republicana que estabelece a primazia da soberania popular sobre as liberdades individuais, como é expresso, por exemplo, no direito penal kantiano; (2) o governo misto entre as três classes políticas que originam as três formas puras de soberania, a realeza que constitui a monarquia, a nobreza que forma a aristocracia e o povo (ou os pobres) que produz a democracia ou governo popular, ainda que os diversos autores considerem diferentemente a sua composição e o modo como 
organizá-las dentro da república. Aristóteles defende uma república mais popular como o governo misto da aristocracia com a democracia e as acomoda na república mediante o princípio de divisão de poderes no qual, aos pobres, compete o legislativo e o judiciário, enquanto, à nobreza, se encarrega do executivo ${ }^{14}$; Rousseau interpreta a divisão de poderes segundo o princípio da vontade geral e considera que o povo unido, na função de legislar, promulgando leis resultantes da vontade geral, deve ser separado da aristocracia, que faz decretos particulares na função de governar ${ }^{15}$. Kant, por outro lado, considera que o princípio de igualdade estabelece que nenhuma pessoa no povo pode coagir outra sem poder ser ao mesmo tempo coagida, com exceção do chefe supremo, que pode coagir sem ser coagido, de modo que somente podem existir duas classes políticas, o chefe supremo, que representa o elemento monárquico, inclusive na forma de um presidente eleito periodicamente, deve exercer o poder executivo elaborando decretos particulares, enquanto o povo unido deve legislar através de deputados eleitos e julgar diretamente por meio do júri popular. (3) o governo das leis, pois, embora as leis sejam resultantes da vontade soberano do povo, esta tem que ser expressa na forma de leis para evitar que prevaleça o arbítrio de maiorias passageiras, por isso, tanto Aristóteles, Rousseau e Kant criticam a democracia, que entendem como o governo exercido diretamente pelo povo, o qual é soberano para tomar qualquer decisão, sem a mediação das leis.

Embora estes princípios do governo republicano estejam presentes na Constituição do EUA, de 1787, Kant critica o caráter indissolúvel da união entre os estado que ela implica. Kant mudou seu ponto de vista sobre o direito das gentes ao longo do tempo, desde uma posição favorável a uma federação de povos submetidos a uma constituição republicana cosmopolita com poder coativo até uma federação permanente de estados republicanos independentes e que pode ser dissolvida a qualquer momento, em virtude de uma série de argumentos: (1) segundo o argumento político, o respeito à lei diminui com o aumento da extensão territorial e, portanto, conduz ou à anarquia ou a um despotismo, por isso, uma federação de povos constitui o maior dos despotismos porque conduz a uma monarquia universal ${ }^{16}$; (2) de acordo com o argumento jurídico, não pode existir uma analogia perfeita entre indivíduos e estados porque os indivíduos devem sair do estado de natureza e se submeter a um soberano no estado civil, mas, embora os estados se encontrem, no plano externo, em estado de natureza, no plano interno, já estão em uma situação jurídica, o que permite que se chegue a uma situação pacífica mediante reformas graduais na constituição que visem se aproximar da constituição republicana ${ }^{17}$; (3) com base no argumento lógico, uma federação de estados seria contraditória, pois, submetidos a um soberano único, todo o direito se reduziria ao direito político (interno ao estado), mas neste caso, a única maneira de realizar o direito das gentes seria justamente pela supressão de todo o direito das gentes ${ }^{18}$. Por conseguinte, a partir destes argumentos, pode-se concluir que Kant se opõe às ideias dos federalistas americanos e considera que a paz depende positivamente de uma confederação de estados soberanos que existiu em um breve período da história americana, compreendido entre a Declaração de Independência de 1776 e a Constituição de 1787.

Por último, a paz também depende positivamente do estabelecimento de um direito cosmopolita, cuja concepção vai sendo modificada ao longo da publicação de suas obras e a ideia inicial de uma constituição republicana cosmopolita termina, na Doutrina do direito, como um mero direito de visita, mas não de permanência, asilo e muito menos de conquista. 


\section{A INEVITÁVEL TENSÃo ENTRE GUERRA E PAZ}

O motivo pelo qual Habermas considera que Kant possui somente um conceito negativo de paz é porque o situa no contexto dos vários tratados da metade do século XVII que constituíram a Paz da Vestfália, a qual mantém o equilíbrio das potências europeias com base em uma razão de estado em que a soberania tem que se afirmar, no plano interno, mediante o poder absoluto do soberano que garante a segurança pública e, no plano externo, através de uma série de guerras prudentes que burle a vigilância recíproca e não desate uma aliança dos demais estados contra o transgressor.

Não obstante, Kant não se encontra no contexto da Paz da Vestfália, pois escreve a obra Rumo à paz perpétua para comemorar o Tratado de Paz da Basileia de $1795^{19}$, o qual põe fim ao conflito entre a França e a Prússia e quebra a unidade de potências europeias que se levantaram contra a Revolução Francesa. A Revolução Francesa rompe com a razão de estado dominante porque a soberania, no plano interno, passa do despotismo absoluto dos reis da França para a vontade soberana do povo e inaugura uma forma de governo republicano em que o súdito é também cidadão, mas que desata um período de matanças políticas conhecido como Terror, no qual se condenam à morte tanto o Rei Luis XVI, quanto membros da nobreza e do clero, assim como antigos partidários da revolução considerados traidores, como um prelúdio do que sucederá nas incontáveis revoluções que marcaram a contemporaneidade, enquanto, no plano externo, desata uma aliança de monarquias preocupadas em evitar a contaminação dos ideais revolucionários, que origina guerras com proporções continentais e até mundiais ${ }^{20}$. Contudo, mesmo antes do Tratado de Paz da Basileia e da publicação de seu opúsculo comemorativo, Kant já havia se manifestado explicitamente contra os princípios da razão de estado imperantes na medida em que critica o chamado equilíbrio das potencias europeias na famosa passagem de Teoria e práxis no qual recorda que ele se parece com a casa de Swift, construída de tal modo segundo as leis do equilíbrio que bastou um simples pardal posar sobre ela que todo o prédio foi derrubado ${ }^{21}$.

Embora Kant entendesse que a Revolução Francesa e a Paz da Basileia representassem a inauguração de um momento histórico distinto para as relações internacionais com respeito à Paz da Vestfália, pois implicava a substituição do seu conceito de razão de estado que fomentava guerras limitadas por guerras ilimitadas, marcadas pelo Terror, ele não pensa em criminalizar a própria guerra justamente porque considera que ela desempenha um papel indispensável na realização dos objetivos da razão prática. Na verdade, longe de criminalizar a guerra, Kant é um de seus maiores enaltecedores, pois, tanto do ponto de vista da história filosófica como da metafísica dos costumes, reconhece que há uma tensão irremediável entre guerra e paz que não pode ser eliminada ${ }^{22}$.

A dicotomia entre a história a priori e a metafísica dos costumes provém da tese do idealismo transcendental apresentado na solução da terceira antinomia, na "Dialética Transcendental" segundo a qual a causalidade pela liberdade é uma ideia reguladora da razão que inicia espontaneamente uma nova série de fenômenos enquanto a causalidade pela natureza mostra como estes fenômenos estão encadeados em uma série infinita de causas e efeitos, as quais constituem duas ordens separadas sem que uma interfira na outra.

Ainda que tenha se tornado comum falar de uma filosofia da história em Kant, 
de fato, ele usa o termo mais adequado de uma "história filosófica" (philosophischen Geschichte) ${ }^{23}$, porque isto descreve melhor a diferença existente entre o idealismo transcendental e a filosofia da história, igualmente relacionada com o conflito, desenvolvida, posteriormente no século XIX, por Hegel e Marx. Enquanto a filosofia da história destes últimos é uma ideia constitutiva, que descreve o surgimento de uma nova forma de organização social baseada na luta pelo reconhecimento e na luta de classes, para o idealismo transcendental a história é a priori na medida em que é narrada a partir da razão prática como uma ideia reguladora que possui um sentido prático, uma vez que indica como devemos agir, mas não possui sentido teórico, uma vez que não apresenta um prognóstico, capaz de ser conhecido independentemente da experiência, sobre os acontecimentos futuros. Portanto, devemos agir "como si" nos aproximássemos assintoticamente do ideal da paz perpétua entre os estados, embora jamais pudéssemos alcançá-lo, já que, quando nos aproximamos de sua realização, percebemos que o objetivo se deslocou para outra perspectiva. Por conseguinte, a paz perpétua também não pode ser interpretada como uma ideia constitutiva da razão que explicará os acontecimentos futuros, mas é uma ideia da razão com indubitável realidade prática que determina o modo como devemos agir ${ }^{24}$.

A história a priori mostra como a natureza, mediante o antagonismo da insociável sociabilidade resultante da natureza humana, marcada, simultaneamente, pela dupla tendência à socialização e a individualidade, auxilia a espécie humana a realizar os desígnios da louvável, mas impotente, razão prática, explicando o progresso humano, inclusive em sentido moral. Pelo conflito da insociável sociabilidade a espécie humana deixa uma vida idílica de pastoreio e, através do trabalho e da discórdia, domina a agricultura e, com isso, ingressa no estado civil, que surge quando um usurpador reúne a multidão selvagem para formar um povo, na medida em que o homem é um animal que precisa de um senhor, o qual suprime o conflito na medida em que detém o monopólio da violência legal, mas, justamente por isso, torna-se despótico e, consequentemente, extingue toda a liberdade dos súditos. Por este motivo, "ainda hoje, a ameaça da guerra é a única coisa que modera o despotismo" 25 . Contudo, o mecanismo da insociável sociabilidade garante que o soberano haja com prudência e faça reformas graduais na legislação vigente, sob pena de que aconteçam revoltas dos súditos, instaurando um despotismo esclarecido no qual o soberano governa de modo republicano "como si" as leis emanassem da própria vontade dos cidadãos, ainda que eles não sejam efetivamente consultados, até que, através de uma aproximação constante, se chegue ao governo republicano no qual o povo promulga a legislação para si próprio.

Da mesma maneira que o conflito da insociável sociabilidade fomenta as reformas graduais na legislação dos estados, a guerra constitui o mecanismo capaz de instituir uma relação internacional pacífica segundo o direito das gentes e o direito cosmopolita, porque o soberano precisa dos impostos dos súditos para promover as guerras, mas estes impostos dependem da geração de riquezas capaz de custear a guerra, o que só é possível com um espírito de liberdade ${ }^{26}$, entendido como liberdade negativa (liberdade econômica e religiosa). Contudo, uma "nova invenção", a dívida externa, na qual os estados contraem dívidas junto a um sistema financeiro internacional permitiu estender a capacidade bélica dos estados além da capacidade tributária dos súditos, transformando as guerras em uma epidemia. Não obstante, como a economia mundial se torna interrelacionada, a bancarrota de um estado pode causar o colapso do sistema financeiro como um todo e, por isso, surge um sistema político de regulação entre os estados capaz de garantir a saúde econômica mundial ${ }^{27}$, a federação 
de estados, como uma associação permanente, mas sempre passível de dissolução, e um direito cosmopolita de visita.

Mas, se a guerra é indispensável para possibilitar as reformas constitucionais, a liberdade dos súditos e paz internacional da perspectiva da história a priori, também é importante do ponto de vista da metafísica dos costumes, pois, apesar do veto da razão prática segundo o qual "não deve haver guerra", Kant considera que há um direito a guerra porque uma guerra justa é uma guerra contra um inimigo injusto, ou seja, aquele que por suas palavras e atos torna impossível a realização da paz. Naturalmente que surgem suspeitas sobre a conciliação entre o veto da razão prática, "não deve haver guerra", que resulta do imperativo categórico, com o direito à guerra contra um inimigo injusto, mas, esta suspeição logo desaparece se considerarmos que se trata de idealismo transcendental, segundo qual o veto da razão prática é somente uma ideia reguladora que orienta as ações, o que significa que os legisladores devem agir segundo este dever estabelecido pela razão prática, do qual a humanidade deverá se aproximar sem, contudo, jamais alcançar, mas não representa um princípio constitutivo que determina institucionalizar um pacifismo radical $^{28}$. Portanto, a humanidade sempre viverá em condições onde a guerra será inevitável, por isso, existe a necessidade de um direito à guerra contra os inimigos injustos.

O mesmo ocorre em relação aos exércitos. Embora Kant considere que o uso de exércitos regulares remunerados constitui uma violação do imperativo categórico porque implica usar a humanidade tanto na sua pessoa (os próprios soldados profissionais) como na pessoa do outro (quando o soberano os envia para a guerra) como mero meio, mas não ao mesmo tempo como um fim em si mesmo, denominandoos mercenários, o qual deve, portanto, ser extinto gradualmente, pois, como um artigo preliminar para a paz perpétua, pode ser adiado provisoriamente já que a sua realização imediata causaria mais prejuízos que benefícios, contudo, isso não significa a eliminação de todo e qualquer efetivo militar, mas a sua substituição por milícias de cidadãos os quais voluntariamente, mas, permanentemente, devem realizar práticas militares para a defesa da pátria ${ }^{29}$. A existência de milícias de cidadãos também é compatível com o veto da razão prática porque este último é uma ideia reguladora da razão que orienta as nossas ações, mas não é um princípio constitutivo que tem que ser institucionalizado pelo governo.

\section{III}

\section{AS CONDIÇÕES ECONÔMICAS E SOCIAIS PARA A PAZ}

Posteriormente, na terceira seção de seu artigo, Habermas apresenta um segundo argumento que explicaria porque Kant apresentou apenas um conceito negativo de paz: "Kant se contentou com um conceito negativo de paz. Mas isto é insatisfatório não apenas porque a guerra perdeu os seus limites, mas principalmente pelo fato de que as guerras têm causas sociais"30. Isto acontece por duas razões: (1) como filósofo do século XVIII, Kant pensaria a-historicamente, sem se preocupar com as causas econômicas, sociais e culturais da guerra, cuja solução é indispensável para a paz ${ }^{31}$ e; (2) Kant imaginou que o cosmopolitismo começaria a partir de uma república em torno da qual se aglutinariam novos estados na medida em que também se tornassem repúblicas pacíficas ${ }^{32}$, as quais formariam uma associação permanente de estados 
independentes. Isto, naturalmente, o dispensava de pensar nas desigualdades econômicas e sociais entre os estados que dificultariam o caminho para a paz, porque somente estados já constituídos previamente como repúblicas se interessariam em fazer parte desta associação de estados.

Evidentemente, que os acontecimentos históricos levaram a formação da associação cosmopolita de maneira diferente daquela perspectiva imaginada por Kant, pois a Organização das Nações Unidas é composta por estados com níveis muito desiguais em termos econômicos, sociais e políticos. Habermas recorda a divisão do mundo em três estados, os quais depois da queda dos governos comunistas no Leste Europeu, precisa ser descrita de maneira diferente. O Terceiro Mundo é formado por aqueles países em que o monopólio da violência legal exercida pelo estado é tão fraco (como ocorre na Somália) ou desmoronou (como aconteceu na antiga Iugoslávia) a tal ponto que as tensões sociais não podem mais ser mantidas dentro do nível de uma política de tolerância, o que alimenta guerras civis baseadas em motivos nacionalistas, étnicos e religiosos, bem como permite o surgimento de formas indiretas de poder aglutinadas ao redor de máfias e narcotraficantes ou de caráter fundamentalista; o Segundo Mundo é formado pelos estados que surgiram do processo de descolonização europeia e que, por outro lado, compensam as tensões internas de natureza étnica ou religiosa mediante instituições autoritárias que não respeitam os direitos humanos e a democracia, bem como, no plano externo, reforçam a sua soberania e independência pelo temor de intervenções estrangeiras. Ambos os grupos de países, evidentemente, não apresentam as condições necessárias para fomentar um projeto cosmopolita. Somente os países do Primeiro Mundo, apresentariam as condições para a realização de um projeto de paz cosmopolita uma vez que, no plano interno, floresce na sociedade civil a tolerância política e religiosa, abre-se espaço para a formação de uma opinião pública e para o exercício da cidadania, e se constitui uma organização política sensível a estas reivindicações, enquanto, no plano externo, cresce a recusa do uso da força militar e o apelo à solução pacífica dos conflitos, bem como a insistência na juridificação das relações internacionais. Consequentemente, Habermas considera que somente o moderno estado democrático de direito, com uma política de respeito aos direitos humanos e à democracia, reúne as condições para promover o cosmopolitismo ${ }^{33}$.

O problema é que, se esta desigualdade não era relevante, para Kant, porque somente estados republicanos adeririam à federação de estados, Habermas parte da situação contemporânea em que a ONU é composta por países com níveis muito desiguais no que se refere à capacidade para superar a guerra como meio de solução de conflitos substituindo-a por meios pacíficos. Por isso, a comunidade internacional precisa hoje fazer uma "abstração real" das condições efetivas dos estados membros na orientação de suas políticas capazes de superar as tensões sociais e as desigualdades econômicas, o que só pode ser conseguido mediante uma série de convergências: tornase necessário desenvolver uma consciência histórica compartilhada que reconheça as diferença entre estes estados que precisam manter relações pacíficas; deve-se formar um acordo normativo acerca dos direitos humanos e; por fim, um consenso em torno do conceito de paz que se deseja ${ }^{34}$.

Por conseguinte, Habermas apresenta uma proposta inspirada em Dieter e Eva Senghaas, que avalia a complexidade de causas da guerra e pretende oferecer uma alternativa para a paz, sem o recurso da violência, capaz não apenas de preveni-la, mas também de constituir uma relação entre povos isenta de tensões. As regulamentações para a solução de conflitos não podem vulnerar a existência, a autoestima, os interesses 
vitais e a sensibilidade das partes a ponto de despertar novamente a violência e; elas devem usar todos os recursos disponíveis, abaixo do limite do emprego direito de forças armadas, com o intuito de fomentar as condições econômicas e sociais capazes de promover o desenvolvimento da democracia, do estado de direito, dos direitos humanos e da tolerância ${ }^{35}$.

Embora esta estratégia de intervenção pacífica conta com o apoio de uma sociedade globalizada em que todos os estados se tornaram interdependentes entre si, bem como de uma consciência histórica de que vivemos em uma sociedade de risco planetário na qual todos podem ser afetados, existem também dificuldades na realização deste projeto: o Conselho de Segurança da ONU deveria ter uma composição capaz de agir coordenadamente; deve-se formar uma opinião pública política que mobilize permanentemente os governos dos estados; é preciso criar organismos regionais que dotem a ONU de uma atuação efetiva e; esta coação pacífica deve ter em conta uma percepção dos riscos mundiais ${ }^{36}$.

Não obstante, apesar das observações de Habermas, Kant considerou (1) que as questões econômicas são relevantes para a paz, só que, segundo a tradição republicana, encontrada também em Aristóteles e em Rousseau, a república instaura uma divisão entre o público e o privado, com base no princípio de que não se pode formar uma vontade geral sobre o que é particular, no qual o soberano não deve interferir no espaço de ação dos súditos, porque, por um lado, somente o povo pode se esclarecer a si próprio, enquanto tanto a guerra quanto a paz dependem de um espírito de liberdade econômico e religioso; (2) além do mais, ele não se preocupou com a "abstração real" porque recusou o modelo de uma organização cosmopolita que tivesse que impor coercitivamente os direitos humanos e a democracia a estados membros heterogeneamente constituídos em termos de condições políticas, econômicas e sociais e pensou que a paz perpétua dependia da institucionalização de uma constituição republicana em um estado determinado ao redor do qual se aglutinariam outros estados republicanos em uma federação de estados soberanos.

Ao contrário da concepção comum defendida pelos liberais de que o pensamento republicano é totalitário, a verdade é que o republicanismo estabelece uma diferenciação entre o público e o privado separando, portanto, entre o domínio da liberdade positiva sujeito à intervenção da soberania popular e o espaço reservado para a liberdade negativa dos súditos, ainda que o faça segundo âmbitos e princípios diferentes. Aristóteles, por exemplo, distinguiu rigorosamente o oikos da polis, pois, se a sociedade doméstica era marcada pela desigualdade entre o homem livre, enquanto animal que fala, governava a sua mulher, cuja fala era destituída de autoridade, dos filhos, cuja fala ainda não estava desenvolvida e dos seus escravos, os quais diferentemente dos animais, que somente têm voz, mas não fala, compreendem a fala, mas não a possuem, a sociedade política era caracterizada por uma associação entre homens livres e iguais. Como observa Hannah Arendt a economia era interpretada por Aristóteles como algo privado e, portanto, não era objeto de interesse do estado e, como parte do processo de despolitização da política empreendida pelos modernos, o estado atual praticamente somente se preocupa com a economia e só discute temas como inflação, desemprego, taxas de juros, etc... ${ }^{37}$; por outro lado, ainda que Rousseau considerasse a economia uma questão politicamente relevante, como, sobre o particular não se pode formar uma vontade geral, representando um limite ao poder soberano ${ }^{38}$, então, o soberano deixa para o arbítrio dos indivíduos a maior parte da atividade econômica.

De acordo com a tradição republicana, Kant defende que deve haver um espaço 
regulado pela vontade unificada do povo, mas, repetindo Rousseau, sobre o particular não se pode formar uma vontade geral, por isso, como a felicidade é um elemento empírico que depende do arbítrio de cada um, então o soberano deve permitir que cada súdito decida acerca de sua felicidade e seu bem-estar do modo que achar melhor ${ }^{39}$. Do mesmo modo, o esclarecimento deve ser negativo, porque a culpa da menoridade reside na preguiça e covardia de cada um e, por isso, preferem que outro pense em seu lugar e decida o que é melhor para ele, os tutores da grande massa. Por isso, o esclarecimento não pode ser o resultado da ação positiva do estado, nem mesmo de mestres, mas basta que os tutores da grande massa não interfiram que o público se esclarece a si próprio ${ }^{40}$. Também o soberano deve permitir que haja, internamente, um espírito de liberdade econômica e religiosa dos súditos como condição para o pagamento de impostos para a guerra, ainda que seja para custear a próxima guerra, contudo, como o espírito comercial é naturalmente pacífico, então ele acaba por obrigar, externamente, a uma regulamentação das relações econômicas que conduz a federação pacífica de estados e; por fim, a liberdade de pluma, deve auxiliar o soberano a interpretar corretamente a vontade unificada do povo, porque, ao contrário do que pensava Hobbes, a vontade geral não pode errar, mas o detentor do poder soberano pode se enganar e cometer injustiças contra o povo ${ }^{41}$. Consequentemente, Kant pensa que a concretização do projeto de paz depende tanto de uma política positiva de republicanização do estado quanto de uma política negativa de não-interferência do estado na esfera privada dos súditos.

Habermas, contudo, tem razão quando diz que Kant não levou em consideração a "abstração real", segundo a qual, em função da desigualdade no desenvolvimento econômico e social dos estados, já que apenas uma parte deles cumpre os requisitos mínimos definidores dos modernos estados democráticos do direito, indispensáveis para a paz, torna-se necessário que uma organização cosmopolita implemente uma série de políticas positivas para fomentar a defesa dos direitos humanos e da democracia, que vão desde a coação forte de ação militar efetiva, passando por sanções dissuasórias, até a coação branda da promoção da melhoria das condições econômicas e sociais nos países subdesenvolvidos. Não obstante, a "abstração real" só é uma exigência dentro das condições do cosmopolitismo estabelecido pelo próprio Habermas, no qual uma organização cosmopolita já existente tem que conviver com estados em diferentes níveis de desenvolvimento econômico e social e que deve zelar por uma política coativa para a garantia da paz, porém, não afeta o projeto kantiano na medida em que o ingresso na federação de estados tem que pressupor uma republicanização prévia do próprio estado.

Em uma famosa passagem de Rumo à paz perpétua, Kant afirmou que:

Se a sorte determinar que um povo forte e ilustrado possa formar uma república... ela pode se tornar o centro de uma federação que, mediante a união de outros estados, assegura a liberdade destes estados, conforme a ideia do direito das gentes, a qual se estenda gradualmente através de outras uniões ${ }^{42}$.

Embora ele não mencione especificamente qual seria esta república ilustrada ao redor da qual se aglutinaria uma federação de estados independentes, é muito provável que Kant esteja se referindo à república instaurada na França depois da Revolução Francesa e não à república nos EUA, em primeiro lugar, devido ao fato do opúsculo ter sido escrito para comemorar o Tratado de Paz da Basileia entre a França e a Prússia, mas principalmente porque, neste momento, o desenrolar dos acontecimentos nos EUA, levaram à vitória dos ideais federalistas tornando as 13 as repúblicas da América do Norte um estado de povos pois, submetidos a uma Constituição e não uma federação de 
estados. Como Kant considera que um estado de povos conduz a uma monarquia universal, pois as leis perdem a eficácia quando aumenta o território governado, o qual precisa ser compensado por um despotismo sem alma que termina em anarquia e elimina todos os germens do bem ${ }^{43}$, então, ele se distancia e critica o modelo americano, mas renova as suas esperanças com os rumos republicanos da Revolução Francesa.

\section{REFERÊNCIAS:}

ARAMAYO, R. (org). La paz y el ideal cosmopolita de la Ilustración: a propósito del bicentenario de "Hacia la paz perpetua" de Kant. Madrid: Tecnos, 1996.

ARENDT, H. The human condition. 2nd ed., Chicago: University Chicago Press, 1958.

ARISTÓTELES. Politica. Madrid: Gredos, 1988.

BENHABIB, S. Kosmopolitismus und Demokratie: Von Kant zu Habermas. Goethe-Institut e. V., Fikrun wa Fann, Juni 2012. Disponível em: $<$ http://www.goethe.de/ges/phi/prj/ffs/the/a97/de9507770.htm>. Acesso em $28 \mathrm{de}$ fev. 2017.

BOHMAN, J. \& LUTZ-BACHMANN, M. Perpetual peace: essay on Kant's cosmopolitism ideal. Massachusetts: The MIT Press, 1997.

CONTRERAS PELÁEZ, F. C. Kant y la guerra: una revisión de la Paz Perpetua desde las preguntas actuales. Valencia: Tirant lo Blanch, 2007.

FINE, R. \& SMITH, W. Jürgen Habermas's Theory of Cosmopolitanism. Constellations, 10(4):469-487, 2003.

-Kantian cosmopolitanism today: John Rawls and Jürgen Habermas on Immanuel Kant's foedus pacificum. The King's College Law Journal 15: 5-22, 2004.

HABERMAS, J. Strukturwandel der Öffentlichkeit. 4.Aufl., Frankfurt am Main, Suhrkamp Verlag, 1995.

—Die Einbeziehung des Anderen. Studien zur politischen Theorie. 2.Aufl., Frankfurt am Main, Suhrkamp Verlag, 1997.

HELD, D. Democracy and the Global Order. Stanford: Stanford University Press, 1995.

KANT, I. Kants Gesammelte Schriften. Hrsg. von der Königlichen Preussischen, bzw. von der Deutschen Akademie der Wissenschaften. Berlin: Walter de Gruyter, 1902 ss.

KLEINGELD, P. Kant's Cosmopolitan Patriotism. Kant-Studien 94: 299-316, Walter de Gruyter, 2003.

KLENNER, H. Kants Entwurf "Zurn ewigen Frieden" - Illusion oder Utopie? Archiv für Rechtsund Sozialphilosophie, 2: 151-160, 1996.

MARTINS, C. A. \& POKER, G. (org.) O pensamento de Habermas em questão. Marília: Oficina Universitária UNESP, 2008.

MERTENS, T. "Cosmopolitanism and citizenship: Kant against Habermas", European Journal of Philosophy, 4 (1996), 328-47.

MORI, M. La pace e la ragione. Kant e le relazioni internazionali: diritto, politica e storia. Bologna: Il Mulino, 2008.

ROUSSEAU, J-J. Du contrat social. Paris: Gallimard, 1964.

Discours sur l'origine et les fondements de l'inégalité parmi les hommes. Paris: Gallimard, 1969.

SCRIVENER, M. The Cosmopolitan Ideal in the Age of Revolution and Reaction, 1776-1832. New York: Pickering and Chatto, 2007.

TOSEL, A. Kant révolutionnaire. Droit et Politique. 2.éd., Paris: PUF, 1990.

VELASCO ARROYO, J. C. Ayer y hoy del cosmopolitismo kantiano. Madrid: Isegoría,16: 91117, 1997.

VLACHOS, G. La pensée politique de Kant. Paris : PUF, 1962.

\section{Notas}


1 Lista de abreviaturas: Zef, Zum ewigen Frieden; MdS, Methaphysic der Sitten; TuP, Über den Gemeinspruch: Das mag in der Theorie richtig sein, taugt aber nicht für die Praxis; BdF: Beantwortung der Frage: Was ist Aufklärung?; IGA: Idee zu einer allgemeinen Geschichte in weltbürgerlicher Absicht; MAM: Mutmaßlicher Anfang der Menschengeschichte.

2 HABERMAS, J. Die Einbeziehung des Anderen. p. 194.

3 HABERMAS, J. Die Einbeziehung des Anderen. p. 194.

4 HABERMAS, J. Die Einbeziehung des Anderen. p. 213.

5 KANT, I. ZeF, p. 346.

6 HABERMAS, J. Die Einbeziehung des Anderen. p. 200.

7 HABERMAS, J. Die Einbeziehung des Anderen. p. 194.

8 HABERMAS, J. Die Einbeziehung des Anderen. p. 213.

9 O que corresponderia respectivamente, ao menos de modo parcial, ao direito interno ao estado, ao direito internacional público e o direito internacional privado.

10 KANT, I. ZeF, p. 351.

11 Segundo alguns autores, Kant somente negaria o direito de resistência depois que a Revolução Francesa se tornou vitoriosa e a constituição republicana de 1791 foi aprovada, tornandose a França o modelo de estado republicano que ele defendia. Isso é confirmado, inclusive, a partir da observação de Kant, segundo a qual, mesmo que o novo soberano tenha surgido de forma ilegítima mediante uma revolução, ainda assim, uma resistência contra a nova ordem, não é legitima. Contudo, embora estas afirmações sejam absolutamente corretas e, certamente, Kant pretendia defender a república instaurada com a Revolução Francesa, mesmo antes da Grande Revolução, Kant já havia manifestado a sua preferência pelas reformas constitucionais graduais em detrimento das revoluções com base no argumento de que estas somente substituem os antigos senhores por novos déspotas e não conduz ao esclarecimento das pessoas.

12 KANT, I. MdS, p. 351.

13 Estas características foram recompiladas a partir de algumas referências comuns encontradas em autores republicanos clássicos como Aristóteles, o Maquiavel dos Discursos sobre Tito Lívio, Rousseau e o próprio Kant.

14 ARISTÓTELES. Política. p.260 et seq.

15 ROUSSEAU, J.-J.. Du contrat social. p. 235.

16 KANT, I. ZeF, p. 367.

17 KANT, I. ZeF, p. 355.

18 KANT, I. ZeF, p. 355.

19 Posteriormente, também em 1795, houve um segundo Tratado de Paz da Basileia que pôs fim ao conflito da França com a Espanha.

20 A Revolução Francesa e as guerras que se seguiram tiveram consequências no processo de independência das colônias europeias na América e inclusive no Brasil, já que a Coroa Portuguesa para retaliar a invasão francesa ocupou, por sua vez, a Guiana Francesa, devolvida em 1817, e o Uruguai, haja visto que Napoleão mandou coroar seu irmão a Espanha, o qual nunca foi devolvido, mas a Província Cisplatina e se tornou independente do Brasil em 1828.

21 KANT, I. TuP, p. 312.

22 As referências favoráveis de Kant à guerra se encontram principalmente em suas obras Ideias para uma história universal em sentido cosmopolita, de 1783, Começo provável da história humana, de 1786, e no "Primeiro Suplemento" de Ruma à paz perpétua, de 1795 .

23 KANT, I. IGA, p. 31.

24 KANT, I. ZeF, p. 362-3.

25 KANT, I. MAM, p. 120.

26 KANT, I. MAM, p. 120.

27 KANT, I. IGA, p. 28.

28 KANT, I. MdS, p. 349.

29 KANT, I. ZeF, p. 345.

30 HABERMAS, J. Die Einbeziehung des Anderen. p. 216. 
31 HABERMAS, J. Die Einbeziehung des Anderen. p. 215. 32 HABERMAS, J. Die Einbeziehung des Anderen. p. 213.

33 HABERMAS, J. Die Einbeziehung des Anderen. p. 215.

34 HABERMAS, J. Die Einbeziehung des Anderen. p. 215.

35 HABERMAS, J. Die Einbeziehung des Anderen. p. 216.

5236 HABERMAS, J. Die Einbeziehung des Anderen. p. 217.

37 ARENDT, H. The human condition. p. 33.

38 ROUSSEAU, J.-J.. Du contrat social. p.195.

ஸे 39 KANT, I. TuP, p. 290.

กे 40 KANT, I. BdF, p. 36.

2. 41 KANT, I. TuP, p. 303-4.

$\infty \quad 42$ KANT, I. ZeF, p. 356.

ন 43 KANT, I. ZeF, p. 367. 